\title{
NORMAL PLANTAR FASCIA THICKNESS IN ADULT
}

\author{
Yusak Mangara Tua Siahaan ${ }^{1,2}$, Pricilla Yani Gunawan ${ }^{1,2}$, Jeffry Foraldy ${ }^{2}$, Veli Sungono ${ }^{2}$ \\ Correspondence: dryusaks2002@gmail.com \\ ${ }^{1}$ Neurology Department of Siloam Hospital Lippo Village, Tangerang, Indonesia \\ ${ }^{2}$ Faculty of Medicine Universitas Pelita Harapan, Tangerang, Indonesia
}

\section{Article History: \\ Received: June 12, 2020 \\ Accepted: September 27, 2021 \\ Published: January 1, 2022 \\ Cite this as: \\ Siahaan YMT, Gunawan PY, Foraldy J, Sungono V. Normal plantar fascia thickness in adult. Malang Neurology Journal; 2022.8:16-20. DOI: \\ http://dx.doi.org/10.21776/ub.mnj 2022.008.01.4}

\section{ABSTRACT}

Background: Plantar fasciitis is a common problem caused by thickening of the plantar fascia. The normal plantar fascia thickness ranged between 2-3 mm and it was generally accepted that value more than $4 \mathrm{~mm}$ was considered pathologic.

Objective: to identify normal plantar fascia thickness in adults using ultrasonography.

Methods: This is a cross sectional study measuring the thickness of plantar fascia in 145 subjects with no history of heel pain. Plantar fascia thickness was measured in both feet using an ultrasound. Age, height and weight were recorded and analysed.

Results: As much as 145 subjects were included in this study. Male to female ratio was 0.7 . Mean age was 44 and body mass index (BMI) was mostly within normal range. Plantar fascia thickness in male was $2.71 \pm 0.48 \mathrm{~mm}$ in right foot, and $2.74 \pm 0.47 \mathrm{~mm}$ in left foot. Fascia thickness in female was 2.55 $\pm 0.50 \mathrm{~mm}$ in right foot, and $2.57 \pm 0.45 \mathrm{~mm}$ in left foot. There was a significant plantar fascia thickness difference between male and female $(p=0.035$ in right foot, and $p=0.04$ in left foot $)$. Age, weight and BMI had a significant correlation towards plantar fascia thickness. In multivariate analysis, age and BMI revealed to have a linear correlation to plantar fascia thickness

Conclusion: Age and BMI were found to be the best predictive factor of plantar fascia thickness.

Keywords: Plantar fascia thickness, plantar fasciitis, ultrasound

\section{Introduction}

Heel pain is a common symptom in clinical practice. One of its most prevalent cause is plantar fasciitis. ${ }^{1}$ In the United States it is estimated that there were roughly two million people suffering from plantar fasciitis and about one from 10 people will experience heel pain in their lifetime. ${ }^{2}$ It is more common in middle-aged women and younger men, especially athletes. ${ }^{3}$ In Indonesia, no data of prevalence was ever published in regards to plantar fasciitis.

Typical classic signs of plantar fasciitis are heel pain early in the morning, pain after a period of inactivity, and pain after a long period of weight bearing position. On physical exam, there may be pain on palpation of medial calcaneal as well as pain when extending the great toe. In most cases, plantar fasciitis is diagnosed based on clinical symptoms and physical examination alone without any need of further investigations. ${ }^{4}$ However, in some cases, patient's complain were not specific enough, bringing up other possibilities such as tarsal tunnel syndrome, radiculopathy, calcaneal stress fracture, and lateral plantar nerve compression. ${ }^{1}$ In these cases, diagnosis could be challenging and ultrasonography is one modality that can be easily performed bedside. It was found that normal plantar fascia thickness is $2-3 \mathrm{~mm}$, and a number $>4 \mathrm{~mm}$ was considered as thickening of fascia $^{5}$ hence the diagnosis of plantar fasciitis.
Plantar fascia thickness can be affected by several factors such as sex, ${ }^{6}$ age, ${ }^{6}$ body mass index (BMI) ${ }^{7,8}$ occupation, ${ }^{9}$ pregnancy ${ }^{10}$ exercise, ${ }^{11}$ and structural abnormalities such as flat foot or high-arched foot. ${ }^{11}$ These factors contribute to the variability of fascia thickness between individual, not to mention in different race. Despite of many data regarding normal fascia thickness available, none has ever been studied upon Indonesian subjects. Theoretically, differences in race, lifestyle, economic, geographic and environment tarsal tunnel syndrome, L5-S1 radiculopathy, calcaneal stress fracture, lateral plantar nerve compression, infection, tumours, and other rheumatology cases tarsal tunnel syndrome, L5-S1 radiculopathy, calcaneal stress fracture, lateral plantar nerve compression, infection, tumours, and other rheumatology cases may result in different fascia thickness.

We find it important to obtain the normal range of plantar fascia thickness as a standard in diagnosing plantar fasciitis. Aside from that, identifying factors that mostly affect plantar fascia thickness may help clinicians in making clinical and therapeutic judgment.

\section{Methods}

This cross-sectional study enrolled 145 subjects without a history of heel pain who visited Siloam Hospital Lippo Village between December 2017 and January 2018. Ethics approval was acknowledged by the institutional clinical research ethic committee of Universitas Pelita Harapan, Tangerang (018/K-LKJ/ETIK/XI/2017). 
Table 1. Subject's characteristic study $(n=145)$

\begin{tabular}{llll}
\hline Subject's characteristic & Male $(\mathbf{n = 6 0})$ & Female $(\mathbf{n = 8 5})$ & $\boldsymbol{P}$ value \\
\hline Age $($ yo) & 43.5 & 44 & .362 \\
Minimum - maximum age (yo) & $21-69$ & $21-66$ & \\
Weight $(\mathrm{kg})$ & 70 & 60 & $<.001$ \\
Minimum - maximum weight & $45-138$ & $42-100$ & \\
Subject by age groups & & & \\
20-29 yo & 16 & 20 & \\
30-39 yo & 8 & 16 & .122 \\
40-49 yo & 10 & 27 & \\
50-59 yo & 19 & 17 & \\
$\geq 60$ yo & 7 & 5 & .462 \\
Subject by BMI groups & & & \\
Underweight & 2 & 6 & \\
Normal & 29 & 46 & \\
Overweight & 21 & 22 & \\
$\quad$ Obese & 8 & 11 & \\
\hline
\end{tabular}

Table 2. Plantar fascia thickness difference between males and females in each foot

\begin{tabular}{lccc}
\hline & $\begin{array}{c}\text { Plantar fascia thickness } \\
\text { Mean } \pm \text { SD }(\mathbf{m m})\end{array}$ & Min - Max $(\mathbf{m m})$ & $\begin{array}{c}\boldsymbol{P} \\
\text { value }\end{array}$ \\
\hline Right foot & & & .035 \\
Male & $2.7132 \pm 0.48006$ & $1.80-3.80$ & \\
Female & $2.5516 \pm 0.49995$ & $1.54-3.90$ & .040 \\
Left foot & & $1.90-3.80$ & \\
Male & $2.7363 \pm 0.47078$ & $1.63-4.00$ & \\
Female & $2.5731 \pm 0.45359$ &
\end{tabular}

Table 3. Plantar fascia thickness based on age groups

\begin{tabular}{lccccc}
\hline & & \multicolumn{2}{c}{ Right foot } & \multicolumn{2}{c}{ Left foot } \\
& Age groups & Mean \pm SD $(\mathbf{m m})$ & Min - Max $(\mathbf{m m})$ & Mean \pm SD $(\mathbf{m m})$ & Min - Max $(\mathbf{m m})$ \\
\hline Plantar & $20-29$ y.o & $2.4069 \pm .42745$ & $1.54-3.40$ & $2.4550 \pm 0.44245$ & $1.63-3.46$ \\
fascia & $30-39$ y.o & $2.4850 \pm .38267$ & $1.90-3.20$ & $2.4746 \pm 0.33473$ & $1.90-3.40$ \\
& $40-49$ y.o & $2.6519 \pm .50129$ & $1.89-3.80$ & $2.7227 \pm 0.45856$ & $1.95-3.70$ \\
& $50-59$ y.o & $2.6914 \pm .42771$ & $1.80-3.70$ & $2.7364 \pm 0.44210$ & $2.07-4.00$ \\
& $\geq 60$ y.o & $3.1983 \pm .60245$ & $1.90-3.90$ & $2.9892 \pm 0.56548$ & $1.90-3.80$ \\
\hline
\end{tabular}

Table 4. Plantar fascia thickness based on BMI groups

\begin{tabular}{lccccc}
\hline & & \multicolumn{2}{c}{ Right foot } & \multicolumn{2}{c}{ Left foot } \\
& BMI groups & Mean \pm SD $(\mathbf{m m})$ & Min - Max $(\mathbf{m m})$ & Mean \pm SD $(\mathbf{m m})$ & Min - Max $(\mathbf{m m})$ \\
\hline Plantar & Underweight & $2.5125 \pm 0.33367$ & $2.10-3.20$ & $2.4875 \pm 0.32600$ & $2.20-3.20$ \\
fascia & Normal & $2.4627 \pm 0.48821$ & $1.54-3.80$ & $2.5213 \pm 0.46790$ & $1.63-3.80$ \\
& Overweight & $2.7340 \pm 0.41361$ & $1.90-3.50$ & $2.7453 \pm 0.42447$ & $2.00-3.70$ \\
& Obese & $3.0168 \pm 0.49492$ & $2.20-3.90$ & $2.9389 \pm 0.07368$ & $2.30-4.00$ \\
\hline
\end{tabular}

Table 5. Correlation of age and weight with left and right plantar fascia thickness

\begin{tabular}{llccc}
\hline & Age & Weight & Height & BMI \\
\hline Right plantar fascia & & & .114 & .442 \\
$\quad$ Correlation coefficient & $.372^{* *}$ & $.393^{* *}$ & .172 & $<.001$ \\
$\quad P$ value & $<.001$ & $<.001$ & & .119 \\
$\quad$ & & $.362^{* *}$ & .155 & .403 \\
$\quad$ Coft plantar fascia & $.347^{* *}$ & $<.001$ & & $<.001$ \\
$\quad P$ value & $<.001$ & &
\end{tabular}

${ }^{* *}$. Correlation is significant at the 0.01 level (2-tailed).

Table 6. Multivariate regression analysis

\begin{tabular}{lcc}
\hline & Coefficients B & $\boldsymbol{P}$ value \\
\hline Right plantar fascia & & \\
Constant & 1.155 & \\
Age & 0.012 & $<.001$ \\
BMI & 0.039 & $<.001$ \\
Left plantar fascia & & \\
Constant & 1.405 & \\
Age & 0.010 & $<.001$ \\
BMI & 0.032 & $<.001$ \\
\hline
\end{tabular}


Individuals were at least 20 years of age and was willing to participate in the research. The exclusion criteria was subject having history of heel pain before measurement, history of any disease on heel region, history of trauma on heel region, and those who refuse to participate. Individuals were well informed about the study and anthropometric measurement was recorded.

The measurement of fascia thickness was conducted by a neurologist who is a Certified Interventional Pain Sonologist. We used Philips Ultrasound Affiniti 70G with a surface transducer of 7.5 and $12 \mathrm{MHz}$. Plantar fascia thickness was measured while patients lying down in a prone position with the foot hanging on the edge of the bed (Figure 1). Fascia thickness was measured $1 \mathrm{~cm}$ distal from the calcaneus (arrow) using a transducer by applying gel beforehand (Figure 2).

\section{Statistical Analyses}

The statistical analyses were calculated using SPSS 24 for Macintosh. The difference in fascia thickness between male and female was examined using the Mann-Whitney test. Wilcoxon test was used to compare the right and left foot. Linear regression analysis was used to determine the variables that had the most significant correlation with fascia thickness.

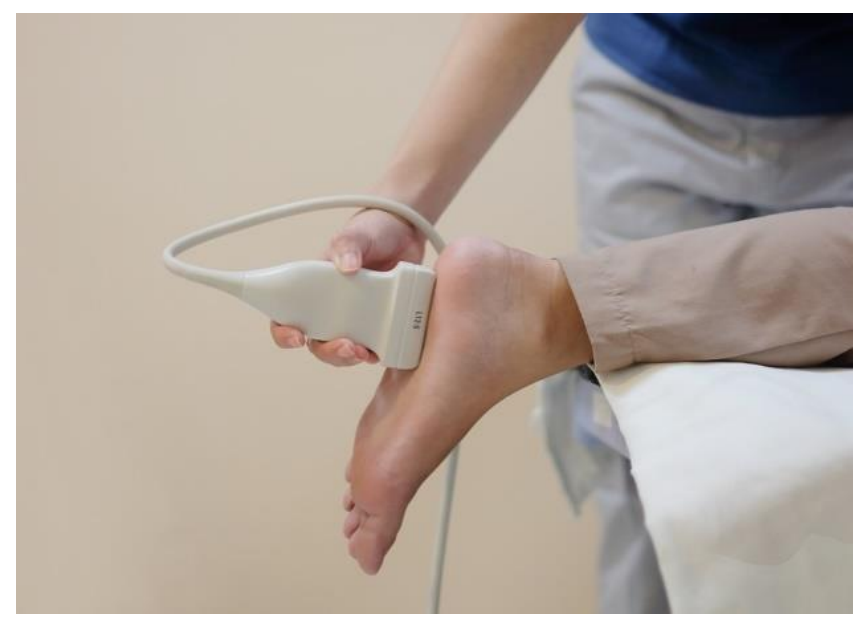

Figure 1. The transducer was hold vertically to the medial side of plantar near the calcaneal origin of the fascia.

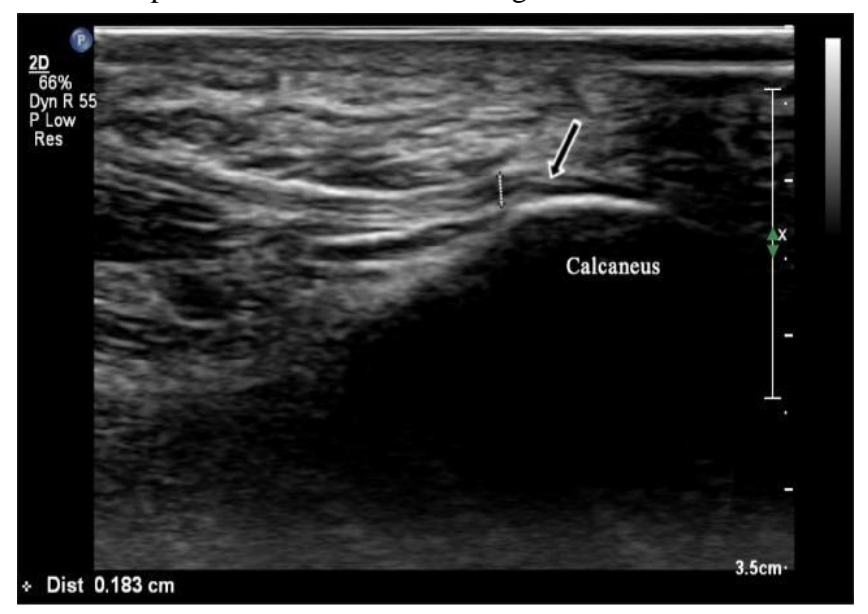

Figure 2. Plantar fascia is shown by arrow, the thickness was measured as $1.83 \mathrm{~mm}$ (dotted line).

\section{Results}

From 145 subjects, as much as 85 of them were women $(58.6 \%)$. The demographic study (Table 1 ) shows mean age was 44 and the range of age was similar between male and female. The distribution in age group was highest in the 5059 years old group in male, and in 40-49 years old group in female. The majority of subjects have a BMI in the normal range. When fascia thickness was analysed based on sex (Table 2), mean thickness for right and left foot was significantly higher in male compared to female. When analysed according to age groups (Table 3), there was an increase in thickness in every escalation of age group. Statistical analysis shows a significant correlation between age groups and fascia thickness. Similar to age, fascia thickness revealed a linear correlation in all groups of BMI, except for underweight groups towards thickness in right fascia (Table 4). Age, weight, and BMI have a significant correlation $(\mathrm{P}<0.05)$ with plantar fascia thickness in both foot (Table 5). The result of multivariate linear regression analysis showed plantar fascia thickness was associated with age and BMI as strongest predictor (Table 6).

\section{Discussion}

Plantar fasciitis is one of the most common ankle pain caused by repetitive stress and compression which leads to thickening of the fascia. Diagnosis of plantar fasciitis is usually based upon history of heel pain and physical examination alone. Recently, high resolution ultrasonography has been widely used to confirm the diagnosis of plantar fasciitis especially in cases of unexplained and dubious pain. Increased plantar fascia thickness as seen in ultrasound has been accepted as diagnostic criteria of plantar fasciitis. The use of ultrasonography is superior to other diagnostic tools (MRI, scintigraphy) since it is cheaper, faster and safer in terms of radiation. ${ }^{12,13,14} \mathrm{~A}$ number of studies indicate that patients with thickness of more than $4 \mathrm{~mm}$ on ultrasonography supports the diagnosis of plantar fasciitis. ${ }^{5}$ In this study, we intend to determine the thickness of plantar fascia in asymptomatic subjects in hope to achieve a normal value of fascia thickness. Although numerous researches had been conducted, few data was available from Indonesia and Southeast Asia.

This study included all patients from different age groups with no history of heel pain to identify plantar fascia thickness across age, gender and body mass index. Although there has been previous study in asymptomatic patients, the number of subjects was far less, hence with less variance in age and body mass. The range of age in this study is $20-65$ years old. The mean thickness of plantar fascia in men is $2,72 \mathrm{~mm}(1.80-3,80 \mathrm{~mm})$ whereas in women is $2.56 \mathrm{~mm}(1.54-3.90 \mathrm{~mm})$. This number does not differ from previous study which shows that plantar fascia thickness was less than $4,0 \mathrm{~mm}$. Huerta et $\mathrm{al}^{15}$ reported that the mean thickness of plantar fascia was between $2.2-3.9$ $\mathrm{mm}$. Gadalla et $\mathrm{al}^{16}$ discovered a thicker fascia in men 3.7 $\mathrm{mm}$ and in women $3.5 \mathrm{~mm}$. This number is equivalent to Balogun et $\mathrm{al}^{15}$ who reported $3.6 \mathrm{~mm}$ as the mean thickness.

Our data suggests that plantar fascia thickness in asymptomatic population is less compared to previous studies. This might be caused by the difference in number 
of subjects, number of samples in younger age group, and perhaps the difference in body mass. The number of subjects in previous studies rarely exceeds 100 (except study by Abul et $\mathrm{al}^{1}$ ). Younger age (less than 40) might also reflect in less thick fascia. Our study does not show any significant difference between mean fascia thickness in right and left both in men and in women. This finding differs with studies by Abul et $\mathrm{al}^{1}$ and Gadalla et $\mathrm{al}^{16}$ who reported that right foot has a significantly thicker fascia than left.

Besides the number of samples and age, the geographic factors in which the study was conducted may also result in different types of activity and exercise. Race is also another factor which contributes to weight and height of the subjects, resulting in variation of fascia thickness in this study. This study found significant differences in fascia thickness between men and women $(P<.05)$, with fascia thicker in men than women in both side of feet. The average thickness of the right foot fascia in men and women was $2.713 \mathrm{~mm}$ and $2.551 \mathrm{~mm}(P=0.035)$, whereas on the left leg was $2.736 \mathrm{~mm}$ and $2.573 \mathrm{~mm}(P=0.040)$. This shows a significant difference $(P<.05)$ between the plantar fascia thickness in both male and female on the right or left side.

This result is in accordance with research conducted by Gadalla et $\mathrm{al}^{16}$ in which male has thicker than women. Differences in body structure between men and women could possibly affect body mass index. In addition, different occupational and activity may also play a role. Different results were obtained in a study by Gadalla et $\mathrm{al}^{16}$ and Serkan et al. ${ }^{17}$ Dhakal et $\mathrm{al}^{18}$ reported there is no significant differences in male and female fascia thickness. The difference in these results may be due to the number of different samples, in which Gadalla et al ${ }^{15}$ study only measures 31 subjects. Serkan et $\mathrm{al}^{18}$ concluded that the plantar fascia thickness in both men and women was statistically similar although gains were slightly lower in women than in men.

This study also showed no significant difference between the thickness of the right and left foot fascia. In men, the average thickness of the right and left foot is $2,713 \mathrm{~mm}$ and $2,736 \mathrm{~mm}(P=0.566)$, in women the average thickness of the right and left foot fascia is $2,551 \mathrm{~mm}$ and $2,573 \mathrm{~mm}(P$ $=0.387)$. These results differed from results reported by Abul et $\mathrm{al}^{1}$ and Gadalla et $\mathrm{al}^{16}$ who reported right-footed legs had greater thickness than the left side. But Dhakal et $\mathrm{al}^{18}$ had a similar result with this study. It was assured that this may be due to relatively similar stress each foot was involved in.

In this study the plantar fascia thickness was statistically significant in each age group $(P<.05)$ There is an increase in the thickness of the fascia in different age groups, where the age of 20-30 years has the lowest average thickness ( $2.406 \mathrm{~mm}$ right leg and 2,455 mm left foot) and age $>60$ years has the highest thickness (right leg $3.198 \mathrm{~mm}$ and left leg 2,989 mm). Increase in the thickness of the fascia is also present in each increase in age group. Similarly Abul et al ${ }^{1}$ reported that there was a significant correlation between the thickness of the plantar fascia and age. Different results were obtained in a study by Huerta et $\mathrm{al}^{15}$ in which age was not related to plantar fascia thickness in asymptomatic samples. The highest plantar fascia thickness obtained at age > 60 years possibly because increase in age would affect the fat pad and structure of heel pad. Fat pad will become smaller especially in the inferior heel, and the structure of heel pad will became less in water, collagen and elastic tissue, hence reducing the ability of shock absorbency and less protection to the calcaneus.

Age and weight are factors that are also associated with plantar fascia thickness. In both bivariate and multivariate analyses, age and weight are significantly related to plantar fascia thickness. Unlike weight, height has no significant correlation to plantar fascia thickness. This is similar to a research by Huerta et $\mathrm{al}^{15}$ which suggests that body weight is a more sensitive parameter in influencing plantar fascia thickness, compared with height.

There was significant relationship between plantar thickness and BMI group $(P<.05)$. The thickness of the plantar fascia increases with the increase of BMI. In samples with normal BMI the average thickness was 2,462 $\mathrm{mm}$ on the right foot and $2,521 \mathrm{~mm}$ on the left foot, whereas in sample with obese, average thickness was 3.016 $\mathrm{mm}$ on the right foot and 2,938 $\mathrm{mm}$ on the left foot. Same results were obtained when multivariate analysis was applied. The results of research conducted by Huerta et a ${ }^{15}$ and Abul et al $^{1}$ also supported the relationship between plantar fascia thickness and BMI. A high BMI is a plausible source of increased stress on the plantar surface. Van Leeuwen et $\mathrm{al}^{20}$ mentions that higher $\mathrm{BMI}$ is associated with plantar fasciopathy. Some studies suggest there is a positive association between plantar fasciitis with overweight $(\mathrm{BMI}>25)$ and obese $(\mathrm{BMI}>30)$.

Multivariate analysis revealed an independent relation between age, weight, and BMI towards right and left fascia thickness. This indicates that age, weight and BMI may predict plantar fascia thickness. Findings in this study could be utilized as a normal value in assessing patients with heel pain problems. Hopefully in the future a similar study can be conducted in a greater scale and with more variables taken into account. The mean thickness of plantar fascia in men and women is $2,72 \mathrm{~mm}$ and $2,56 \mathrm{~mm}$ respectively.

\section{Conclusion}

There was a significant difference of plantar fascia thickness between male and female on the right or left foot. Age and BMI are the strongest predictive factors in estimating plantar fascia thickness.

\section{Conflict of Interest}

The author reports no conflicts of interest in this work.

\section{Acknowledgement}

Our gratitude to Pamela Tiffani for helping the data collection and Universitas Pelita Harapan and Siloam Hospitals Lippo Village, Tangerang, Indonesia for facilitating this research.

\section{References}

1. Abul K, Ozer D, Sakizlioglu SS, Buyuk AF, Kaygusuz MA. Detection of normal plantar fascia thickness in adults via the ultrasonographic method. Journal of the American Podiatric Medical 
Association; 2015. 105(1):8-13. DOI: $10.7547 / 8750-$ 7315-105.1.8

2. Riddle DL, Pulisic M, Pidcoe P, Johnson RE. Risk factors for plantar fasciitis. The Journal of Bone and Joint Surgery-American Volume; 2003. 85(5):872-7. DOI: $10.2106 / 00004623-200305000-00015$

3. Tahririan MA, Motififard M, Tahmasebi MN, Siavashi B. Plantar fasciitis. Journal of Research in Medical Sciences: The Official Journal of Isfahan University of Medical Sciences; 2012. 17(8):799-804. PMID:23798950

4. Schwartz EN, Su J. Plantar fasciitis: A concise review. The Permanente Journal; 2014. 18(1):e105-7. DOI: $10.7812 / \mathrm{TPP} / 13-113$

5. Hossain M, Makwana N. "Not Plantar Fasciitis": The differential diagnosis and management of heel pain syndrome. Orthopaedics and Trauma Journal; 2011. 25(3):198-206. DOI: 10.1016/j.mporth.2011.02.003

6. Young CC, Rutherford DS, Niedfeldt MW. Treatment of plantar fasciitis. American Family Physician; 2001. Feb 1;63(3):467-74, 477-8. PMID: 11272297

7. Frey C, Zamora J. The Effects of obesity on orthopaedic foot and ankle pathology. Foot \& Ankle International; 2007;28(9):996-9.

DOI: 10.3113/FAI.2007.0996

8. Fuller EA. The windlass mechanism of the foot: A mechanical model to explain pathology. Journal of the American Podiatric Medical Association; 2000. 90(1):35-46. DOI: 10.7547/87507315-90-1-35

9. Wearing SC, Smeathers JE, Yates B, Sullivan PM, Urry SR, Dubois P. Sagittal movement of the medial longitudinal arch is unchanged in plantar fasciitis. Medicine \& Science in Sports \& Exercise; 2004. 36(10):1761-7.

DOI: $10.1249 / 01 . m s s .0000142297 .10881 .11$

10. Marnach ML, Ramin KD, Ramsey PS, Song SW, Stensland JJ, An KN. Characterization of the relationship between joint laxity and maternal hormones in pregnancy. Obstetrics \& Gynecology; 2003. 101(2):331-5. DOI: 10.1016/s00297844(02)02447

11. Fillipou D, Kalliakmanis A, Triga A, Rizos A, Grigoriadis E. Sport related plantar fasciitis. current diagnostic and therapeutic advances. Folia Medica; 2004. 46(3):56-60. PMID: 15819459

12. Radwan A, Wyland M, Applequist L, Bolowsky E, Klingensmith H, Virag I. Ultrasonography, an effective tool in diagnosing plantar fasciitis: A systematic review of diagnostic trials. International Journal of Sports Physical Therapy; 2016. 11(5):663671. PMID: 27757279

13. Siahaan YMT, Ketaren RJ, Hartoyo V, Tiffani P. The predisposing factors of piriformis syndrome: Study in a referral hospital. MNJ; 2019. 5(2): 76-9.

DOI: 10.21776/ub.mnj.2019.005.02.5

14. Santoso WM, Rakhmatiar R, Rakhmani AN, Sahidu MG. Comparison of the effectiveness of therapy in hydrodissection injection using ultrasonography guidence between normal saline and triamcinolone in carpal tunnel syndrome patients. MNJ; 2020. 6(1): 59. DOI: 10.21776/ub.mnj.2020.006.01.2

15. Huerta JP, García JMA, Matamoros EC, Matamoros JC, Martínez TD. Relationship of body mass index, ankle dorsiflexion, and foot pronation on plantar fascia thickness in healthy, asymptomatic subjects. Journal of the American Podiatric Medical Association; 2008. 98(5):379-85.

DOI: $10.7547 / 0980379$

16. Gadalla DN, Kichouh M, Boulet C, Machiels F, Mey JD, Maeseneer MD. Sonographic evaluation of the plantar fascia in asymptomatic subjects. Journal of the Belgian Society of Radiology; 2014. Jan;97(5):271. DOI: $10.5334 /$ jbr-btr. 1326

17. Bisi-Balogun A, Cassel M, Mayer F. Reliability of various measurement stations for determining plantar fascia thickness and echogenicity. Diagnostics; 2016. 6(2):15. DOI: 10.3390/diagnostics6020015

18. Dhakal GR, Parajuli NP, Joshi KS, Shrestha R, Sherchan B. Sonographic measurement of normal plantar fascia thickness in healthy nepalese population. Journal of Manmohan Memorial Institute of Health Sciences; 2016. Sep;2:37-44.

DOI: 10.3126/jmmihs.v2i0.15795

19. Taş S, Bek N, Onur MR, Korkusuz F. Effects of body mass index on mechanical properties of the plantar fascia and heel pad in asymptomatic participants. foot \& ankle international; 2017. 38(7):779-84.

DOI: $10.1177 / 1071100717702463$

20. Leeuwen KDBV, Rogers J, Winzenberg T, Middelkoop MV. Higher body mass index is associated with plantar fasciopathy/'plantar fasciitis': systematic review and meta-analysis of various clinical and imaging risk factors. British Journal of Sports Medicine; 2015. Jul;50(16):972-81.

DOI: $10.1136 /$ bjsports-2015-094695 